EDITOR

David Jewell, BA, MRCGP

Bristol

DEPUTY EDITOR

Alec Logan, FRCGP

Motherwell

JOURNAL MANAGER

Catharine Hull

SENIOR ASSISTANT EDITOR

Erika Niesner

ASSISTANT EDITOR

Moira Davies-Cinar

EDITORIAL ASSISTANT

Tania Marszalek

ADVERTISING EXECUTIVE

Brenda Laurent

DISPLAY ADVERTISING SALES EXECUTIVE

David Cox

CLASSIFIED ADVERTISING SALES EXECUTIVE

Peter Wright

EDITORIAL BOARD

Richard Baker, MD, FRCGP

Leicester

Stephen Barclay, MD, FRCGP, DRCOG

Cambridge

Chris Butler, MD, MRCGP

Cardiff

Kath Checkland, PhD, MRCGP

Manchester

Mark Gabbay, MD, FRCGP

Liverpool

Clare Gerada, MBE, FRCGP, MRCPsych

London

Roger Jones, FRCP, FRCGP, FFPHM, FMedSc

London

Murray Lough, MD, FRCGP

Glasgow

David Mant, MD, FRCGP

Oxford

Tim Peters, MSc, PhD, cStat, FFPH

Bristol

Chris Salisbury, MD FRCGP

Bristol

John Sandars, MSc, MD, FRCGP, MRCP

Leeds

Mark Shapley, FRCGP, DCH, DRCOG

Newcastle-under-Lyme

Niroshan Siriwardena, MMedSci, PhD,

FRCGP

Lincoln

Theo Verheij, MD, PhD, MRCGP

Utrecht, The Netherlands

Sue Wilson, BA, PhD, PGA

Birmingham

2007 impact factor: 2.229

EDITORIAL OFFICE

14 Princes Gate, London SW7 1PU

(Tel: 0207581 3232, Fax: 0207584 6716).

E-mail: journal@rcgp.org.uk

http://www.rcgp.org.uk/bjgp

PUBLISHED BY

The Royal College of General Practitioners,

14 Princes Gate, London SW7 1PU. Registered charity number 223106. The BJGP is published by the RCGP, but has complete editorial

independence. Opinions expressed in the BJGP should not be taken to represent the policy of

the RCGP unless this is specifically stated.

No endorsement of any advertisement is implied or intended by the RCGP.

PRINTED IN GREAT BRITAIN BY

HPM Limited, Prime House, Park 2000,

Heighington Lane Business Park,

Newton Aycliffe, Co. Durham DL5 6AR.

Printed on $100 \%$ recycled paper
For more than 20 years, if my memory serves, we GPs in the UK have been berated for failing to diagnose depression in our patients. Numerous interventions have been found to be ineffective in improving our rates of identification. A paper we published in 2005 found that the diagnosis was not made in half of patients with possible major depression. ${ }^{1}$ An earlier paper in the BMJ suggested that one of the reasons is that the patients themselves may be reluctant to reveal their depressive symptoms, ${ }^{2}$ a view echoed in a study of postnatal depression. ${ }^{3}$ Identifying the problem is only the beginning and this month we are publishing a cluster of papers exploring the difficulties of management. According to the group in Norwich, looking at indicators of quality, the standard of care is variable: almost everyone was offered treatment, but fewer than half had an assessment of suicide recorded (page 94). We have become more willing to prescribe antidepressants. In an earlier paper a group from Scotland had charted a large rise in the numbers prescribed (but in the absence of an increase in diagnoses). ${ }^{4}$ Here they find predictable variation between doctors in their prescribing: less for patients from ethnic minorities and lower rates among practices with larger patient lists (page 88). As they say, 'the difficulty with determining the correct prescribing level of antidepressants ... is that there are many gaps in the evidence base ...'; or, in other words, we simply don't know. Even when we prescribe antidepressants, the patients do what they always do, and make their own sense of the advice they've taken away with them. In the Dutch study on page 81 we learn that $4 \%$ of patients prescribed antidepressants never had the pills dispensed, and a further $23 \%$ didn't return for a second prescription. I suspect this will echo the experience of many readers certainly many of my own patients stop taking the antidepressants much sooner than the guidelines recommend. We've known for a long time that patients instinctively prefer talking therapies, and the review on page 120 summarises the benefits of psychological treatment. The effect size comes to an NNT of 5.75; is that better or worse than you would have expected? Interesting, in terms of policy, that when the patients were identified by screening, the effects were close to zero. People writing systematic reviews have to consider how to group the different treatments, and grouping all psychological treatments together as they have done may not do justice to the current market leader (CBT). But on page 133, Sara
Dryburgh wonders if the current love affair with CBT is the right approach. Her view is that it pays too little attention to the human psyche's need to find meaning in illness.

All of this is set in context in the editorial on page 76. Jed Boardman concludes that we may need to follow a fairly lengthy course of different treatments to ensure the maximum benefit for all. But he adds 'Given the limited effect, sizes of available treatments, and the need to try multiple approaches ... Balint's idea of "the Doctor is the Drug" needs to be enhanced (and broadened to include the whole health care team).' We are back with the fundamentals of good general practice: being a good generalist means applying high grade generalist skills as well as high levels of specialist knowledge (pages 79 and 99). It also means being good at the unmeasurable stuff as well as the measurable stuff, but here in the UK we are currently being managed by a government department that wants to whip us all into line on the measurable indicators, and appear not to have the slightest interest in the unmeasurable ones. They are vigorously taken to task this month, by both Mike Fitzpatrick (page 139) and Emyr Gravell (page 144). The unmeasurable gets an airing in the account of heartsink relationships on page 136, where the authors point out that such experiences are completely idiosyncratic. It also shines out of the lecture on page 128, where Don Berwick pays homage to his father's style of practice, suffused with love and care for his patients but, he thinks, unable to survive in today's climate of target indicators.

Classics corner: last month we had Virgil. This month it's Homer in the reference on

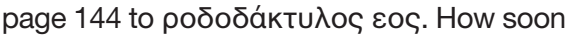
before we set off across the wine-dark sea?

\section{David Jewell}

Editor

\section{REFERENCES}

1. Kendrick T, King F, Albertella L, Smith PW. GP treatment decisions for patients with depression: an observational study. Br J Gen Pract 2005; 55: 280-286.

2. Kessler D, Lloyd K, Lewis G, Gray DP. Cross-sectional study of symptom attribution and recognition of depression and anxiety in primary care. BMJ 1999; 318: 436-439.

3. Shakespeare J, Blake F, Garcia J. A qualitative study of the acceptability of routine screening of postnatal women using the Edinburgh Postnatal Depression Scale. Br J Gen Pract 2003; 53: 614-619.

4. Munoz-Arroyo R, Sutton M, Morrison J. Exploring potential explanations for the increase in antidepressant prescribing in Scotland using secondary analyses of routine data. Br J Gen Pract 2006; 56: 423-428.

DOI: 10.3399/bjgp09X395030

c) British Journal of General Practice 2009: 59: 73-152. 